\title{
Influence of estrous cycle on explorative behaviour of wild-type and prodynorphin knockout mice Iris Rosskothen ${ }^{1}$, Eduard Schunk ${ }^{1}$, Stefano Gaburro ${ }^{2}$, Nicolas Singewald ${ }^{2}$, Herbert Herzog ${ }^{3}$ and Christoph Schwarzer*1
}

\author{
Address: ${ }^{1}$ Department of Pharmacology, Innsbruck Medical University, 6020 Innsbruck, Austria, ${ }^{2}$ Department of Pharmacology and Toxicology, \\ University of Innsbruck, 6020 Innsbruck, Austria and ${ }^{3}$ Garvan Institute of Medical Research, Sydney, New South Wales 2010, Australia \\ Email: Christoph Schwarzer* - schwarzer.christoph@i-med.ac.at \\ * Corresponding author
}

from I4th Scientific Symposium of the Austrian Pharmacological Society (APHAR)

Innsbruck, Austria. 21-22 November 2008

Published: 5 November 2008

BMC Pharmacology 2008, 8(Suppl I):A6 doi:I0.1 I86/I47I-22I0-8-SI-A6

This abstract is available from: http://www.biomedcentral.com/I47I-22I0/8/SI/A6

(C) 2008 Rosskothen et al; licensee BioMed Central Ltd.

Since several years dynorphin, a member of the opioid peptide family, was suggested to play a regulatory role in numerous functional pathways of the brain. In line with its localization in hippocampus, amygdala, hypothalamus and striatum these functions resemble learning and memory, emotional control and stress response. Male prodynorphin-deficient (Dyn KO) mice display an anxiolytic phenotype [see abstract A5]. However, emotional control and stress response depend on hormonal state and differ between sexes. In female rodents mood is influenced also on the estrous state. We now analysed the explorative behaviour in correlation to the estrous cycle in female wild-type (WT) and prodynorphin knockout mice. In the open field test WT mice showed significantly more anxiety during the estrous. This effect is abolished in Dyn KO mice. No differences were seen throughout the other stages. In the elevated plus maze test Dyn KO mice showed a significant anxiolytic phenotype regarding time spent, distance traveled and entries in the open arm at all estrous stages compared to WT mice. In addition, WT mice showed a significant decrease in all parameters during proestrous and estrous. This increased anxiety is attenuated by prodynorphin deficiency. In the light-dark test WT mice showed a decrease in time spent and distance traveled in the lit area during proestrous. In contrast, $\mathrm{KO}$ mice behaved relatively stable throughout the stages. Our data indicate an anxiolytic phenotype also in female Dyn KO mice. However, the phenotype is less prominent than in male mice and appears to be dependent on estrous stage and paradigm. It is interesting to note that the influence of the estrous stage appears to be abolished by the prodynorphin deficiency. The functional and pharmacological background will be investigated in further experiments. 